\title{
Anti-Proliferative Effects of Human Anti-FZD7 Single Chain Antibodies on Colorectal Cancer Cells
}

\author{
Mehdi Fazeli, ${ }^{1}$ Neda Zarei, ${ }^{1}$ Bahareh Moazen, ${ }^{2,3}$ and Foroogh Nejatollahi ${ }^{2,3,{ }^{*}}$ \\ ${ }^{1}$ Department of Biotechnology, School of Veterinary Medicine, Shiraz University, Shiraz, IR Iran \\ ${ }^{2}$ Shiraz HIV/AIDS Research Center, Institute of Health, Shiraz University of Medical Sciences, Shiraz, IR Iran \\ ${ }^{3}$ Recombinant Antibody Laboratory, Department of Immunology, Shiraz University of Medical Sciences, Shiraz, IR Iran \\ "Corresponding author: Foroogh Nejatollahi, Shiraz HIV/AIDS Research Center, Institute of Health, Shiraz University of Medical Sciences, Shiraz, IR Iran. E-mail: nejatollaf \\ @sums.ac.ir
}

Received 2017 January 05; Revised 2017 February 14; Accepted 2017 February 20.

\begin{abstract}
Background: Colorectal cancer (CRC) accounts for the third most common cancer-related death in human. Wnt growth factors signaling have an important role in the CRCs' development. Frizzled family receptor 7 (FZD7) belongs to the 10-member Frizzled (FZD) family of receptors and has an important role in triggering Wnt signaling. Antibody-therapy is an important class of modern medicine. Human single chain antibodies, which are composed of VH-Linker-VL are small antigen-binding units with unique properties, which overcome monoclonal antibodies and are applied for certain cancer immunotargeting approaches.

Objectives: This study aimed at determining the anti-tumor properties of 2 anti-FZD7 scFvs phage antibodies.

Methods: Two specific anti-FZD7 scFv antibodies were assessed for their anti-cancer effects. Flow cytometry was used to investigate the binding ability of scFvs to SW-480 colorectal cancer cell line, and SKBR3 cells, as the negative FZD7 cell line. Cell proliferation assay was performed to evaluate the growth inhibition effects of the different concentrations of anti-FZD7scFv phage antibodies (1000 to 4000 phage/cell). Mann-Whitney U test was used to compare percentages of cell growth between treated and untreated cells.

Results: Fluorescent activated cell sorting(FACS) analysis revealed that scFv I and II bound to $62.4 \%$ and $63.7 \%$ of SW-480 cells, respectively, whereas $6.4 \%$ and $8.3 \%$ bound to SKBR-3 cells, as the negative control. Results of MTT assays on SW-480 demonstrated growth inhibition of 53\%, 63\%, and $83 \%$ for scFv I (3000 phage/cell) after 24,48 , and 72 hours, respectively, while scFv II (4000 phage/cell) treatment showed growth inhibition of $33 \%, 47 \%$, and $63 \%$ for the same period of time, respectively. No significant inhibitory effect for scFvs on the cell growth of SKBR-3 cells was observed $(\mathrm{P}<0.05)$.

Conclusions: Targeted therapy using antibodies has been considered as a new cancer immunotherapy in the recent years. In this study we applied 2 anti-FZD7 antibodies to assess their effect on colorectal cancer cells. Results demonstrated that both scFvs bound to the SW-480 colorectal cancer cell expressing FZD7 receptor. Significant cell growth inhibition for both anti-Fdz7 scFvs after 72 hours of incubation with the optimum amounts of the antibodies was detected. The stronger potential of scFv I for inhibiting the growth of cancer cells was also obtained. The use of scFvs against colorectal cancer cells offers a therapeutic potential for these antibodies in colorectal cancer immunotherapy.
\end{abstract}

Keywords: Colorectal Cancer, Anti-FZD7 scFv, Growth Inhibition, Immunotherapy

\section{Background}

Colorectal cancer (CRC) is one of the most frequently diagnosed cancers among humans, which accounts for the third cause of cancer-related deaths (1). Several studies have shown that mutations of Adenomatouspolyposis Coli (APC) or $\beta$-catenin (CTNNB1) genes, downstream factors in the canonical Wnt signalling pathway, are the main causes of sporadic colorectal cancers $(2,3)$. However, suppressing Wnt signaling by blocking upstream ligands and receptors of this pathway has been effective in the growth and survival of colon cancer cells (4-6).

In Wnt signaling, interaction of frizzled receptor with 1 of the 19 Wnt isoforms results in animal cells' differentiation, polarity determination and cell proliferation modu- lation. Frizzled family receptor 7 (FZD7) belongs to the 10member Frizzled (FZD) family of receptors (7). They all contain an N-terminal, which acts as a signal peptide, an extracellular cysteine-rich domain (CRD) that binds to Wnt ligands, an intracellular C-terminal PDZ domain, to interact with disheveled (Dvl) and a 7-pass transmembrane domain $(7,8)$.

Although FZD7 expression is limited in normal tissues $(9,10)$, recent studies suggest that it is predominantly expressed in several cancer cells, including colon cancer ( 9 , $11,12)$.

Currently, scFvs (single-chain fragment variable) are widely used for diagnostic and therapeutic applications, and include $35 \%$ of antibodies, which are applied in clini- 
cal trials $(13,14)$. Single chain antibodies, which are composed of VH-Linker-VL, are small antigen binding units with unique properties, including human origin, not eliciting HAMA reaction (human anti-mouse antibody response), high specificity, affinity properties, deep penetration in solid tissues, easy manipulation, and economic cost production in prokaryotes (15-19). Recent studies have shown the important role of these antibodies in cancer immunotherapy (20-24).

\section{Objectives}

This study aimed at evaluating the anti-proliferative effects of 2 human-specific anti-FZD7 scFvs, available at our laboratory (article in process), on SW-480 colorectal cancer cell line.

\section{Methods}

\subsection{Cell Culture}

Human colorectal cancer cell line SW-480, an FZD7 expressing cell line, and also SKBR-3 cell line, a breast cancer cell line, as FZD-negative cells, were obtained from the national cell bank of Iran, Pasteur institute of Iran (Tehran, Iran). The cell lines were cultured in RPMI-1640 medium containing $10 \%$ fetal bovine serum, $100 \mathrm{U} \mathrm{mL}^{-1}$ streptomycin and $100 \mathrm{mg} \mathrm{mL}^{-1}$ penicillin at $37^{\circ} \mathrm{C}$, in a $\mathrm{CO}_{2}$ incubator.

\subsection{Evaluating Cell Binding Ability by Flow Cytometry}

To evaluate the cell surface binding ability of the selected scFvs in comparison with a commercial anti-FZD7 antibody (Abcam, UK), flow cytometry analysis was used. Briefly, $200 \mu \mathrm{L}$ of either of the selected-scFv antibodies $\left(10^{11} \mathrm{pfu} / \mathrm{mL}\right)$ or commercial rabbit-anti-FZD7 polyclonal antibody were added to $2 \times 10^{5}$ cancer cells and incubated at $4{ }^{\circ} \mathrm{C}$ for 1 hour. Cells were treated with M13KO7 helper phage and used as an isotype control. After washing with ice-cold Phosphate Buffered Saline (PBS), and addition of rabbit anti-fd antibody (Sigma-Aldrich, Germany), they were incubated at room temperature for 30 minutes, followed by 30 minutes of incubation with PE-conjugated anti-rabbit antibody. After washing, the amount of bound phage was measured by a FACS Calibur (BD Biosciences, USA).

\subsection{Cell Proliferation Assay}

Overall, 104 colorectal cancer cells (SW-480) were poured in a 96-well plate (NUNC, Denmark). Plates were set in triplicates. The plates were incubated overnight at $37^{\circ} \mathrm{C}$. Different concentrations of selected phage antibody $(1011 \mathrm{pfu} / \mathrm{mL})$ were then added to the cells and incubated for 24,48 , and 72 hours at $37^{\circ} \mathrm{C}$. Furthermore, $100 \mu \mathrm{L}$ of $0.5 \mathrm{mg} / \mathrm{mL}$ MTT reagent (3-(4, 5-dimethylthiazol-2-yl)-2,5diphenyltetrazolium bromide) (Sigma-Aldrich, Germany) was added and incubated at $37^{\circ} \mathrm{C}$ for 4 hours. After removing supernatants, solubilization of the purple crystal products was performed using DMSO (Merck, Germany) for 20 minutes at room temperature. Colorimetric determination was assessed at $570 \mathrm{~nm}$ using the Enzyme-Linked Immunosorbent Assay (ELISA) reader (BP-800, Biohit, USA). The absorbance values obtained for untreated and treated cells were used to calculate the percentage of cell growth inhibition as follows:

Percentage of cell growth inhibition $=1$ - (Optical density 570 treated/optical density 570 untreated $) \times 100$

\subsection{Statistical Analyses}

Mann-Whitney $U$ test was used for comparing the means of percentages of cell growth between antibodytreated and untreated cells. Data are shown as the mean \pm standard deviation. P values of less than 0.05 were considered significant.

\section{Results}

4.1. Flow Cytometric Analysis for Cell Binding Property of AntiFZD7 SCFvs

Flow cytometry assay revealed the binding of both selected anti-FZD7 phage-antibodies and anti-FZD7commercial Ab on colorectal cancer cell line, SW-480. The SKBR-3 cell line was used as the negative control. There was no significant shift in fluorescent intensity of SKBR-3 cells treated with anti-FZD7-scFv or commercial antibody. The ScFv I and II bound to $62.4 \%$ and $63.7 \%$ of SW-480 cells and $6.4 \%$ and $8.3 \%$ of SKBR-3 cells, respectively. The fluorescence intensities obtained from M13KO7-treated cells, as isotype control, was 21\% (Figure 1).

\subsection{Anti-Proliferative Effects of Anti-FZD7 scFvs}

Different concentrations of anti-FZD7 scFvs were applied on SW-480 and SKBR-3 cell lines and the antiproliferative effects are presented in Figures 2 and 3. After 24, 48 and 72 hours of treatment of cells with each phage antibody, the percentages of cell growth inhibition were detected. The scFv I and scFv II significantly inhibited the growth of the SW-480 cancer cells in comparison with the untreated cells and SKBR-3 cell line as the control $(\mathrm{P}<$ 0.05). Treatment with scFv I (3000 phage/cell) resulted in $53 \%, 63 \%$, and $83 \%$ growth inhibition of SW-480, after 24 , 48 , and 72 hours, respectively. The scFv II (4000 phage/cell) treatment resulted in 33\%, 47\% and, 63\% growth inhibition of SW-480, respectively. No significant inhibitory effect of 
Commercial Anti-Fzd7 Antibody
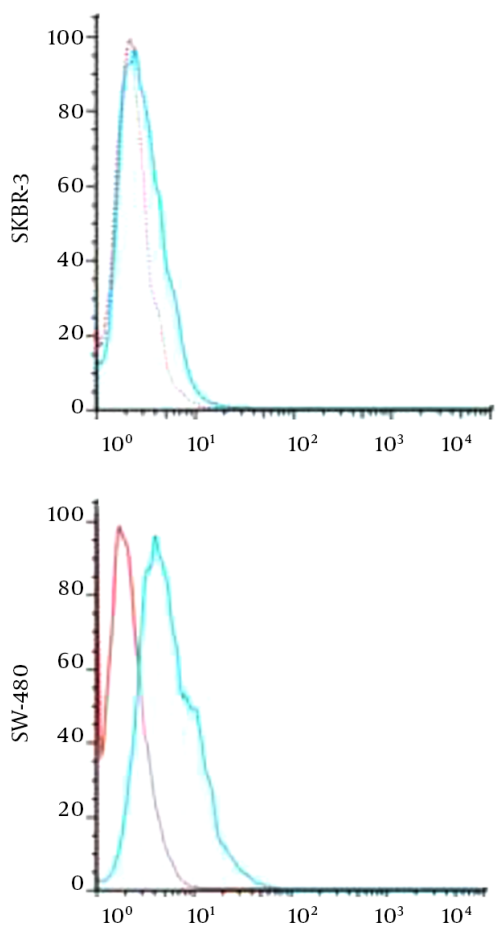

ScFv I
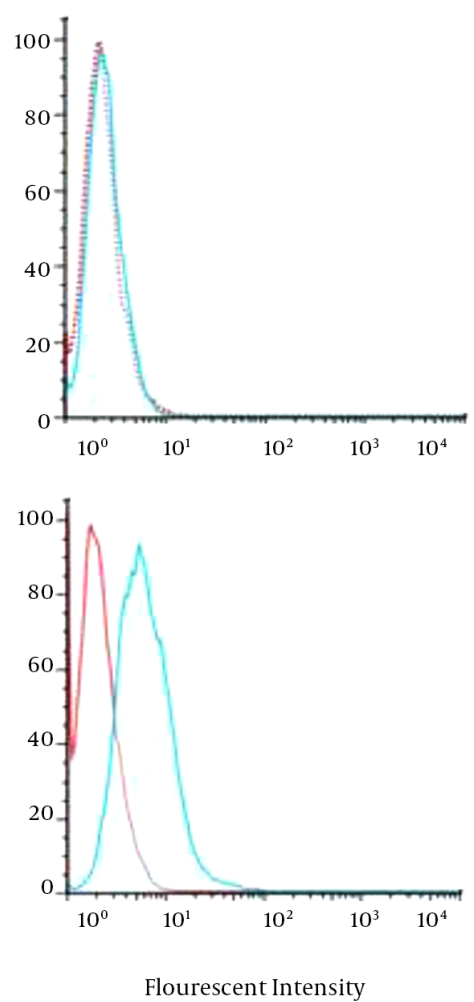

Flourescent Intensity
ScFv II
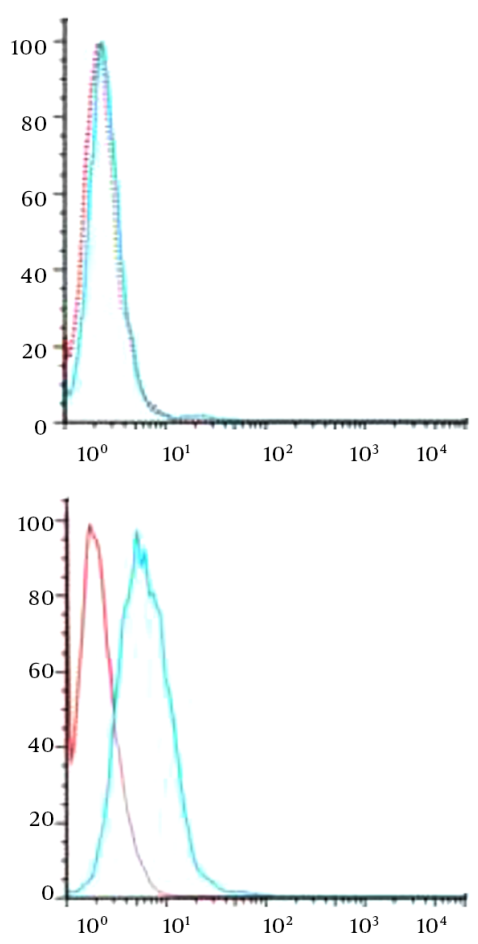

The cell lines were treated with either anti-Fzd7-commercial Ab or anti-Fzd7- scFvs. The fluorescent intensity detected for 2 scFvs and commercial Ab bound to the SW-480 cells showed a shift compared to the intensity of the isotype, cells treated with M13KO7 helper phage, while the fluorescent intensities of the scFvs and commercial Ab overlapped the isotype intensity when SKBR3 cells were treated.

scFvs on the cell growth of SKBR-3 cells was observed $(\mathrm{P}<$ 0.05). The percentages of growth inhibition of SKBR-3 cells after 24,48 , and 72 hours of treatment with scFv I (3000 phage/cell) were $20 \%, 20 \%$, and $32 \%$, and that of scFv II ( 4000 phage/cell) was $11 \%, 22 \%$, and $27 \%$, respectively.

\section{Discussion}

Recent studies have suggested that canonical Wnt signaling pathway is over-activated through FZD7 receptor in many cancers including colorectal, hepatocellular carcinoma (HCC), triple negative breast cancer (TNBC), esophageal cancer, gastric cancer, and Wilm's tumor cell (25-30).

Suppressing Wnt signaling either through Wnt ligand blocking or FZD7 receptor knockdown or soluble peptide fragments to antagonize FZD7 has always been advantageous as a potential strategy to treat FZD7-dependent can- cers (31). However, several obstacles including adverse immune responses of whole antibody therapy have to be considered when using this technology for cancer treatment (32). Targeting specific receptors, which are overexpressed in tumor cells is a safe method of combating cancer (33). One effective method is antagonizing the receptor through soluble peptide fragments. Antibody-therapy is an important class of modern medicine. However, the disadvantages of monoclonal antibodies, including low tissue penetration, production costs, and some side effects $(34,35)$, have led to the development of new effective approaches to improve these drawbacks. One effective approach to block Wnt signaling is developing agents to inhibit receptor-ligand interaction. Among different agents, human scFvs has been shown to have high anti-tumor growth activities, which suggest the advantages of these antibodies as proper tools in targeted therapies (36). The small size of selected scFvs, their human origin, tissue pen- 


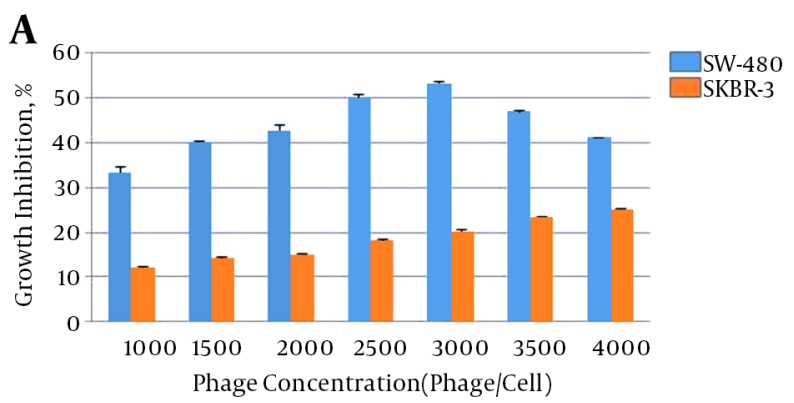

B

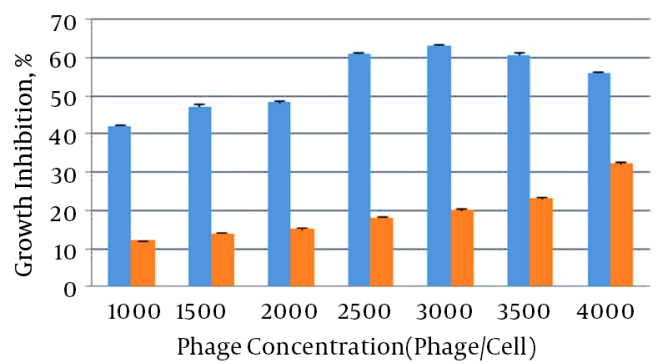

C

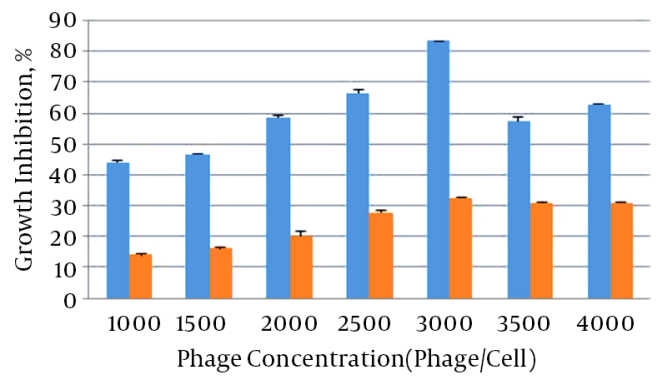

Figure 2. Growth Inhibition of SW-480 Colorectal Cancer Cells Treated With Different Concentrations of Phage scFv I After A, 24; B, 48; and C, 72 Hours Compared to the SKBR-3 Negative Cell Line

etration, and ability to be manipulated by genetic engineering are some of the important advantages of these agents.

To evaluate the effects of anti-FZD7 antibodies, their binding to the cancer cell line was investigated. Flow cytometric analysis indicated that the anti-FZD7-scFv I and II antibodies bound to $62.4 \%$ and $63.7 \%$ of SW-480 cancer cells while their bindings to SKBR-3 was $6.4 \%$ and $8.3 \%$, respectively. The obtained results are consistent with the FZD7 expression level of these cell lines. According to previous studies, FZD7 receptor is overexpressed in SW-480 cell line while its expression in SKBR-3 is low $(9,37)$. Vincan et al. (12) reported on the abundant expression of FZD7 in SW-480 colorectal cancer cells, which activates Wnt/FZD signaling pathway and leads to cellular processes such as cell differentiation, adhesion, and motility. These

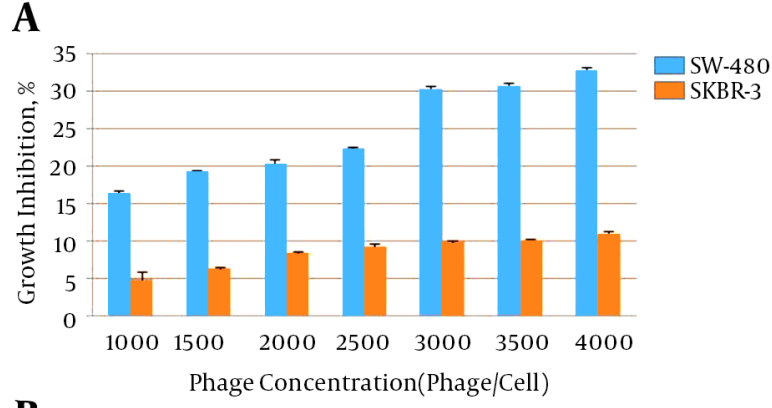

B

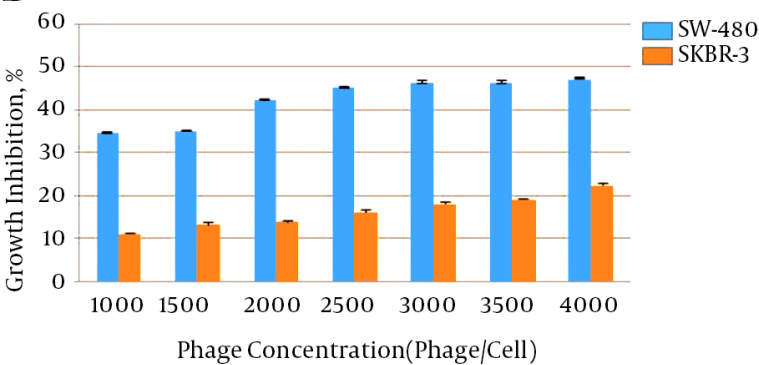

C

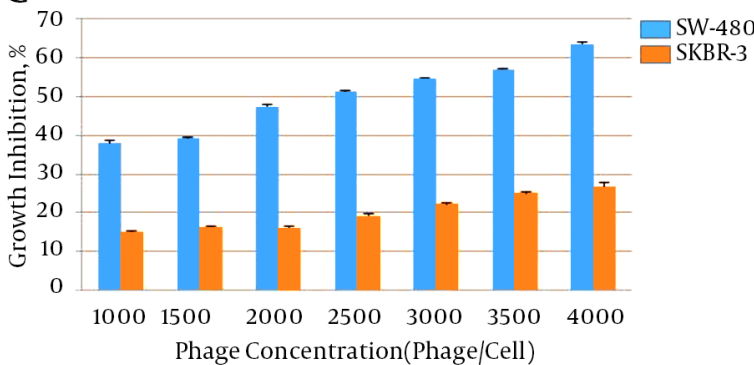

Figure 3. Growth Inhibition of SW-480 Colorectal Cancer Cells Treated With Different Concentrations of Phage scFv II After A, 24; B, 48; and C, 72 Hours Compared to SKBR-3 Negative Cell Line

processes are central to epithelial-mesenchymal transition (EMT) and Mesenchymal-epithelial transition (MET), therefore, tumor growth and progression occurs. The lack of FZD7 on SKBR-3 breast cancer cells and its presence on triple negative breast cancer (TNBC) cells demonstrated by Yang et al. (37), indicated the important role of this receptor in the proliferation of TNBC cells and immunotherapy against FZD7 as an important treatment strategy in triple negative breast cancer.

Over-expression of FZD7 in colorectal cancer implies that this receptor may be involved in the carcinogenesis of this cancer and might be critical for the growth of these cells (7). Studies have demonstrated that FZD7 has a vital role in preserving self-renewal capacity of embryonic stem cells and it can be used as a novel embryonic stem cellspecific surface antigen (38). This study evaluated the anti- 
proliferative potential of anti-FZD7 scFv antibodies. Cell treatment with anti-FZD7 phage-antibodies decreased the growth of SW-480 cancer cells. The optimum concentration for scFv I was 3000 phages/cell, and that of scFvII was 4000 phages/cell. Following 72 hours of incubation of SW480 cancer cells with the optimum concentrations of scFv I and scFv II, considerable cell growth inhibition of $83 \%$ and $63 \%$ was observed. Regarding the effect of scFvI, due to very high concentration of phage antibody above 3000 phages/cell, an adverse effect was observed. No significant effect on cell growth of SKBR-3 negative cell line was observed for either of these scFv-antibodies. Similarly, knockdown of FZD7 expression by siRNA has resulted in the reduction of colon cancer metastasis $(9,39)$. It has also been reported that inhibition of FZD7 using a dominant negative extracellular domain blocks the growth of human colon cancer cells in vitro and in xenograft animal models (11). Moreover, FZD7 shRNA gave rise to a significant suppression of $\mathrm{Wnt} / \beta$-catenin signaling and subsequent cell proliferation and tumor growth in vivo using TNBC cells (37). The results of this study showed that both scFvantibodies were able to exert anti-proliferative effects on SW-480 colorectal cancer cells. However, comparing these 2 scFvs indicates the stronger potential of scFv I on inhibiting the growth of cancer cells. These effects are mainly via the activation of the canonical Wnt signaling pathway. According to Pode-Shakked et al. (30), inhibition of FZD7 using a blocking antibody leads to a reduction in clonality of cancer cells and induces apoptosis in cells expressing FZD7.

Identification of a proper antigen for targeted therapy is a key concept (40). The extracellular part or CRD domain of FZD receptors, which act as binding sites for Wnt ligands, can be targeted by peptides to inhibit binding of wnt ligands thus preventing $\mathrm{Wnt} / \beta$-catenin signaling. It has been shown that targeting of special parts of some extracellular domains of cancer cell receptors leads to anti-proliferative effects $(36,40-42)$. The specificity of tumor binding and anti-proliferative properties of the selected scFvs suggests that these human high affinity and small anti-FZD7 scFvs might have a therapeutic potential for colorectal cancer targeting therapy. The results of this study are in accordance with other recent findings suggesting that inhibiting Wnt signaling through blocking of FZD7 will suppress Wnt signal-mediated cell proliferation in cancer cells. Further studies are needed to show the in vivo effects of these antibodies.

\section{Acknowledgments}

This study was financially supported by Shiraz University of Medical Sciences and Shiraz University. The present article was extracted from the thesis written by Neda Zarei (grant number 9667).

\section{Footnote}

Conflict of Interest: The authors declare that there were no conflicts of interest.

\section{References}

1. Hisamuddin IM, Yang VW. Molecular Genetics of Colorectal Cancer: An Overview. Curr Colorectal Cancer Rep. 2006;2(2):53-9. [PubMed: 19079560].

2. Segditsas S, Tomlinson I. Colorectal cancer and genetic alterations in the Wnt pathway. Oncogene. 2006;25(57):7531-7. doi: 10.1038/sj.onc.1210059. [PubMed: 17143297].

3. Schneikert J, Behrens J. The canonical Wnt signalling pathway and its APC partner in colon cancer development. Gut. 2007;56(3):417-25. doi: 10.1136/gut.2006.093310. [PubMed: 16840506].

4. Bafico A, Liu G, Goldin L, Harris V, Aaronson SA. An autocrine mechanism for constitutive Wnt pathway activation in human cancer cells. Cancer Cell. 2004;6(5):497-506. doi: 10.1016/j.ccr.2004.09.032. [PubMed: 15542433].

5. Suzuki H, Watkins DN, Jair KW, Schuebel KE, Markowitz SD, Chen WD, et al. Epigenetic inactivation of SFRP genes allows constitutive WNT signaling in colorectal cancer. Nat Genet. 2004;36(4):417-22. doi: 10.1038/ng1330. [PubMed:15034581].

6. He B, You L, Uematsu K, Xu Z, Lee AY, Matsangou M, et al. A monoclonal antibody against Wnt-1 induces apoptosis in human cancer cells. Neoplasia. 2004;6(1):7-14. [PubMed: 15068666].

7. King TD, Zhang W, Suto MJ, Li Y. Frizzled7 as an emerging target for cancer therapy. Cell Signal. 2012;24(4):846-51. doi: 10.1016/j.cellsig.2011.12.009. [PubMed: 22182510].

8. Polakis P. Wnt signaling and cancer. Genes Dev. 2000;14(15):1837-51. [PubMed: 10921899].

9. Ueno K, Hiura M, Suehiro Y, Hazama S, Hirata H, Oka M, et al. Frizzled7 as a potential therapeutic target in colorectal cancer. Neoplasia. 2008;10(7):697-705. [PubMed: 18592008].

10. Sagara N, Toda G, Hirai M, Terada M, Katoh M. Molecular cloning, differential expression, and chromosomal localization of human frizzled-1, frizzled-2, and frizzled-7. Biochem Biophys Res Commun. 1998;252(1):117-22. doi: 10.1006/bbrc.1998.9607. [PubMed: 9813155].

11. Vincan E, Darcy PK, Smyth MJ, Thompson EW, Thomas RJ, Phillips WA, et al. Frizzled-7 receptor ectodomain expression in a colon cancer cell line induces morphological change and attenuates tumor growth. Differentiation. 2005;73(4):142-53. doi: 10.1111/j.14320436.2005.00015.x. [PubMed: 15901282].

12. Vincan E, Darcy PK, Farrelly CA, Faux MC, Brabletz T, Ramsay RG. Frizzled-7 dictates three-dimensional organization of colorectal cancer cell carcinoids. Oncogene. 2007;26(16):2340-52. doi: 10.1038/sj.onc.1210026. [PubMed: 17016432].

13. Ahmad ZA, Yeap SK, Ali AM, Ho WY, Alitheen NB, Hamid M. scFv antibody: principles and clinical application. Clin Dev Immunol. 2012;2012:980250. doi: 10.1155/2012/980250. [PubMed: 22474489].

14. Monnier P, Vigouroux R, Tassew N. In Vivo Applications of Single Chain Fv (Variable Domain) (scFv) Fragments. Antibodies. 2013;2(2):193-208. doi: 10.3390/antib2020193.

15. Nejatollahi F, Malek-Hosseini Z, Mehrabani D. Development of single chain antibodies to P185 tumor antigen. Iran Red Crescent Med J. 2008;2008(4):298-302. 
16. Mohammadi M, Nejatollahi F. 3D structural modeling of neutralizing ScFv against glycoprotein-D of HSV-1 and evaluation of antigenantibody interactions by bioinformatic methods. Int J Pharm Bio Sci. 2014;5(4):835-47.

17. Moazen B, Ebrahimi E, Nejatollahi F. Single Chain Antibodies Against gp55 of Human Cytomegalovirus (HCMV) for Prophylaxis and Treatment of HCMV Infections. Jundishapur J Microbiol. 2016;9(3):ee16241. doi: 10.5812/jjm.16241. [PubMed: 27217918].

18. Mohammadi M, Nejatollahi F, Sakhteman A, Zarei N. Insilico analysis of three different tag polypeptides with dual roles in scFv antibodies. J Theor Biol. 2016;402:100-6. doi: 10.1016/j.jtbi.2016.04.016. [PubMed: 27113782].

19. Cheng Y, Li Z, Xi H, Gu T, Yuan R, Chen X, et al. A VL-linker-VH Orientation Dependent Single Chain Variable Antibody Fragment Against Rabies Virus G Protein with Enhanced Neutralizing Potency in vivo. Protein Pept Lett. 2016;23(1):24-32. [PubMed: 26497316].

20. Nejatollahi F, Silakhori S, Moazen B. Isolation and Evaluation of Specific Human Recombinant Antibodies from a Phage Display Library against HER3 Cancer Signaling Antigen. Middle East J Cancer. 2014;5(3):137-44.

21. Mohammadi M, Nejatollahi F, Ghasemi Y, Faraji SN. Anti-Metastatic and Anti-Invasion Effects of a Specific Anti-MUC18 scFv Antibody on Breast Cancer Cells. Appl Biochem Biotechnol. 2017;181(1):379-90. doi: 10.1007/s12010-016-2218-1. [PubMed: 27565656].

22. Li K, Zettlitz KA, Lipianskaya J, Zhou Y, Marks JD, Mallick P, et al. A fully human scFv phage display library for rapid antibody fragment reformatting. Protein Eng Des Sel. 2015;28(10):307-16. doi:10.1093/protein/gzv024. [PubMed: 25991864].

23. Nejatollahi F, Jaberipour M, Asgharpour M. Triple blockade of HER2 by a cocktail of anti-HER2 scFv antibodies induces high antiproliferative effects in breast cancer cells. Tumour Biol. 2014;35(8):7887-95. doi: 10.1007/s13277-014-1854-8. [PubMed: 24828011].

24. Cianfriglia M, Fiori V, Dominici S, Zamboni S, Flego M, Luisa Dupuis M, et al.CEACAM1 is a Privileged Cell Surface Antigen to Design Novel ScFv Mediated-Immunotherapies of Melanoma, Lung Cancer and Other Types of Tumors. Open Pharm J. 2011;6(1).

25. Bengochea A, de Souza MM, Lefrancois L, Le Roux E, Galy O, Chemin I, et al. Common dysregulation of Wnt/Frizzled receptor elements in human hepatocellular carcinoma. Br J Cancer. 2008;99(1):143-50. doi: 10.1038/sj.bjc.6604422. [PubMed:18577996].

26. Yang L, Kim CCH, Yen Y. FZD7 in triple negative breast cancer cells. INTECH Open Access Publisher; 2011.

27. Tanaka S, Akiyoshi T, Mori M, Wands JR, Sugimachi K. A novel frizzled gene identified in human esophageal carcinoma mediates APC/betacatenin signals. Proc Natl Acad Sci U S A. 1998;95(17):10164-9. [PubMed: 9707618].

28. Kirikoshi H, Sekihara H, Katoh M. Up-regulation of Frizzled-7 (FZD7) in human gastric cancer. Int JOncol. 2001;19(1):111-5. [PubMed:11408930].

29. Khan NI, Bradstock KF, Bendall LJ. Activation of Wnt/beta-catenin pathway mediates growth and survival in B-cell progenitor acute lymphoblastic leukaemia. Br J Haematol. 2007;138(3):338-48. doi: 10.1111/j.1365-2141.2007.06667.x. [PubMed: 17614820].

30. Pode-Shakked N, Harari-Steinberg O, Haberman-Ziv Y, Rom-Gross E, Bahar S, Omer D, et al. Resistance or sensitivity of Wilms' tumor to anti-FZD7 antibody highlights the Wnt pathway as a possible therapeutic target. Oncogene. 2011;30(14):1664-80. doi: 10.1038/onc.2010.549. [PubMed: 21472018].

31. Tiwary S, Xu L. FRIZZLED7 Is Required for Tumor Inititation and Metastatic Growth of Melanoma Cells. PLoS One. 2016;11(1):e0147638. doi:10.1371/journal.pone.0147638. [PubMed: 26808375].

32. Dai H, Wang Y, Lu X, Han W. Chimeric Antigen Receptors Modified T-Cells for Cancer Therapy. J Natl Cancer Inst. 2016;108(7) doi: 10.1093/jnci/djv439. [PubMed: 26819347].

33. Younesi V, Nejatollahi F. Induction of anti-proliferative and apoptotic effects by anti-IL-25 receptor single chain antibodies in breast cancer cells. Int Immunopharmacol. 2014;23(2):624-32. doi: 10.1016/j.intimp.2014.10.015. [PubMed: 25466271].

34. Nelson PN, Reynolds GM, Waldron EE, Ward E, Giannopoulos K, Murray PG. Monoclonal antibodies. Mol Pathol. 2000;53(3):111-7. [PubMed: 10897328].

35. Ehsaei B, Nejatollahi F, Mohammadi M. Specific Single Chain Antibodies Against A Neuronal Growth Inhibitor Receptor, Nogo Receptor 1: Promising New Antibodies for the Immunotherapy of Multiple Sclerosis. Shiraz E-Med J. 2017;18(1)

36. Nejatollahi F, Abdi S, Asgharpour M. Antiproliferative and apoptotic effects of a specific antiprostate stem cell single chain antibody on human prostate cancer cells. J Oncol. 2013;2013:839831. doi: 10.1155/2013/839831. [PubMed: 24391668].

37. Yang L, Wu X, Wang Y, Zhang K, Wu J, Yuan YC, et al. FZD7 has a critical role in cell proliferation in triple negative breast cancer. Oncogene. 2011;30(43):4437-46. doi: 10.1038/onc.2011.145. [PubMed: 21532620].

38. Van Hoof D, Dormeyer W, Braam SR, Passier R, Monshouwer-Kloots J, Ward-van Oostwaard D, et al. Identification of cell surface proteins for antibody-based selection of human embryonic stem cell-derived cardiomyocytes. J Proteome Res. 2010;9(3):1610-8. doi: 10.1021/pr901138a. [PubMed: 20088484].

39. Ueno K, Hazama S, Mitomori S, Nishioka M, Suehiro Y, Hirata H, et al. Down-regulation of frizzled-7 expression decreases survival, invasion and metastatic capabilities of colon cancer cells. Br J Cancer. 2009;101(8):1374-81. doi: 10.1038/sj.bjc.6605307. [PubMed: 19773752].

40. Ranjbar R, Nejatollahi F, Nedaei Ahmadi AS, Hafezi H, Safaie A. Expression of Vascular Endothelial Growth Factor (VEGF) and Epidermal Growth Factor Receptor (EGFR) in Patients With Serous Ovarian Carcinoma and Their Clinical Significance. Iran J Cancer Prev. 2015;8(4):ee3428. doi: 10.17795/ijcp-3428. [PubMed: 26478789].

41. Nejatollahi F, Ranjbar R, Younesi V, Asgharpour M. Deregulation of HER2 downstream signaling in breast cancer cells by a cocktail of anti-HER2 scFvs. Oncol Res. 2013;20(8):333-40. doi: 10.3727/096504013X13657689382734. [PubMed: 23924853].

42. Carrasco-Garcia E, Saceda M, Martinez-Lacaci I. Role of receptor tyrosine kinases and their ligands in glioblastoma. Cells. 2014;3(2):199235. doi: 10.3390/cells3020199. [PubMed: 24709958]. 